A N N A L E S Annales de Bretagne et des Pays de l'Ouest

119-4 | 2012

Varia

\title{
Fortunes urbaines
}

Jean Quiénart

\section{OpenEdition}

Journals

Édition électronique

URL : http://journals.openedition.org/abpo/2535

DOI : $10.4000 / a b p o .2535$

ISBN : 978-2-7535-2236-7

ISSN : 2108-6443

Éditeur

Presses universitaires de Rennes

Édition imprimée

Date de publication : 31 décembre 2012

Pagination : 154-155

ISBN : 978-2-7535-2234-3

ISSN : 0399-0826

Référence électronique

Jean Quiénart, «Fortunes urbaines », Annales de Bretagne et des Pays de l'Ouest [En ligne], 119-4 | 2012, mis en ligne le 31 décembre 2012, consulté le 09 juillet 2020. URL : http://journals.openedition.org/ abpo/2535

Ce document a été généré automatiquement le 9 juillet 2020

(c) Presses universitaires de Rennes 


\title{
Fortunes urbaines
}

\author{
Jean Quiénart
}

\section{RÉFÉRENCE}

Bourquin, Laurent et Hamon, Philippe (dir.), Fortunes urbaines. Élites et richesses dans les villes de l'Ouest à l'époque moderne, Rennes, Presses universitaires de Rennes, 2011, 216 p., ISBN 978-2-7535-1696-0, $16 €$.

1 Ce volume est le fruit de journées d'études dont Philippe Hamon et Laurent Bourquin définissent dans une substantielle introduction les cadres - un Grand Ouest suffisamment homogène, tout en offrant un panel de cités de taille et de fonctions différentes - et les axes. Évoquant des débats anciens, ils en restent sagement à une conception pragmatique des élites, tenant compte de la naissance, de la fortune, de situations familiales, des activités professionnelles, des fonctions collectives, et enfin de la taille des villes : présentée par Frédérique Pitou, la fortune des élites « discrètes » du Maine est relativement modeste à côté de celle de leurs homologues nantaises évoquées par Vincent Gallais à travers les Du Bois de la Musse père et fils, premiers présidents à la chambre des comptes de Bretagne, rouennaises que décrit Olivier Chaline, ou rennaises traitées par Gauthier Aubert... Plusieurs communications mettent cependant l'accent sur la difficulté d'estimer un patrimoine, en particulier son passif, et plus encore ses revenus et son évolution dans le moyen et le long terme.

2 Les sources de l'enrichissement sont sans surprise la terre, la robe et l'office, la marchandise et le négoce. Les élites se construisent et se perpétuent dans la polyactivité, grâce à la solidité de réseaux familiaux où s'affirme la conscience qu'elles ont d'elles-mêmes. Ces trois éléments se conjuguent différemment dans des sociétés, des espaces et des temps eux-mêmes divers. Les élites du Maine viennent du monde de l'office ou de celui des affaires (négociants en toile de Laval, en étamine du Mans, négociants en bougie, maîtres de forges), et d'une aristocratie modeste et en repli. À Rouen, la richesse se fonde sur la terre et les maisons; le commerce reste vulnérable à la menace anglaise. À Rennes, G. Aubert décèle vers 1610-1620 les prémices d'une 
cassure qui rompt la continuité sociale et culturelle unissant l'hôtel de ville et les hommes de loi du présidial et du parlement, dont la création aurait détourné vers des activités au service des robins les moyens financiers consacrés en d'autres villes au commerce. L'incapacité de la bourgeoisie marchande à s'intégrer au parlement, et la pression de la noblesse allogène, expliqueraient le précoce exclusivisme nobiliaire, spécifique de la cour de Rennes. Entre robe et négoce, les rapports diffèrent également selon les villes : les alliances sont ainsi bien moins fréquentes à Rouen qu'à Bordeaux.

La fortune sous-tend l'influence politique: les riches, souligne Philippe Jarnoux à propos de la Basse-Bretagne à la fin du xvie siècle, sont les banquiers des institutions, surtout lors des guerres (comme celle de la Ligue en Bretagne). Ils échangent de fait les risques financiers contre une place dans les cercles du pouvoir, qui élargit leur réseau de relations. Les riches ont leurs modes de consommation et d'habitat spécifiques; la ségrégation sociale par l'habitat, déjà marquée à Rouen, est cependant variable, et on investit souvent plus volontiers dans une résidence rurale qu'à la ville. On peut sans doute étendre à d'autres villes les remarques faites à propos de la Normandie ou du Maine: la réussite, l'opulence doivent être suggérées plus qu'imposées: «La manifestation judicieuse de la richesse compte autant que la possession» (p. 52). [« [....] une fortune, écrit encore 0 . Chaline, suppose d'être acceptée par le consensus social » (ibid.) : d'où l'importance des signes symboliques, comme la place occupée à l'église ou la participation aux œuvres de la paroisse. La culture des robins, estime F. Pitou, est assez éloignée des valeurs de l'argent, alors qu'ils investissent dans l'éducation des enfants, qui combine précepteur, collège et maîtres privés. Les riches ont des devoirs : leur éthique évite la vaine ostentation et fait sa part à l'intérêt collectif, qu'il s'agisse des œuvres charitables ou de la participation aux institutions.

Les deux dernières parties se consacrent aux gens d'Église et au négoce. Accordés aux hiérarchies de la société d'ordres, viennent d'abord, grâce à Cédric Michon, les prélats de la première moitié du xvie siècle, suivis des chanoines des cathédrales bretonnes au xviii siècle, dont parle Olivier Charles, et enfin du rapport à l'argent d'un chanoine connu des historiens du Mans, Pierre Nepveu de la Manouillère. Bien des abbayes, qu'on peut cumuler, ont un revenu supérieur à celui d'un diocèse, d'où l'attachement des bénéficiaires aux maisons en commende, attribuées par le roi. Le concordat de Bologne, en ruinant le principe de l'élection, laisse à ce dernier le choix des bénéficiaires. Rares sont les postulants qui tentent dès lors de contourner la volonté royale. Obtenir un évêché suppose un travail de recherche, des réseaux d'informateurs, la mesure des concurrents éventuels et la connaissance de ses revenus et des charges qui le grèvent. Il y a des grands cumulards, tel Jean de Lorraine, qui tient douze évêchés et neuf abbayes. À leur niveau, bien plus modeste, les chanoines bretons, aux revenus en fait fort inégaux, font globalement plus ou moins pâle figure à côté des chapitres les plus riches, voire de nombreux recteurs dans certains diocèses. 0 . Charles met en miroir les classiques de la théologie morale et les exemples locaux pour dessiner, entre "la nécessaire discrétion liée à l'état ecclésiastique et la légitime ostentation afférant à l'ordre social » (p. 139), le rapport des chanoines à l'argent, aux dépenses somptuaires et à la rente. Ils recherchent le confort, l'agrément, le plaisir de pouvoir recevoir, bref un "art de vivre" plutôt que les apparences tapageuses. Entourés de livres, les chanoines écrivent également: Sylvie Granger analyse les trois premières décennies (1759-1789) du journal de Nepveu de la Manouillère. Elle y traque les occurrences des "mots de l'argent ", de la fortune et de la pauvreté, thème au fil des ans de plus en plus présent dans le texte. Les chiffres semés ça et là esquissent les niveaux ressentis de la 
fortune : on n'est «pas riche " avec 600 livres de rente ; mais on est déjà "peu riche " ou « assez riche" avec 3000 , très riche avec 40000 ou 50000 livres (p. 161). L'échelle s'affine des inflexions liées au coût local de la vie, à la situation familiale ou matrimoniale, au patrimoine, aux "espérances ", à la convenance des alliances, dont l'équilibre des fortunes est un des facteurs. La richesse, conclut S. Granger, est pour le chanoine « un curseur majeur, quoique non unique, pour situer les individus sur son échelle de l'estime» (p. 168).

Pour illustrer le monde des affaires, Benoît Hubert se fonde sur une autre source familière aux historiens du Maine, les mémoires de Leprince d'Ardenay, publiés en 2007 par les Presses universitaires de Rennes sous le titre Mémoires d'un notable manceau au siècle des Lumières 1737-1817 (Benoît Hubert [éd.]). Issu d'une famille aux origines « opaques », le manufacturier Leprince d'Ardenay, associé en 1763 à la manufacture de cires et bougies de son père, lui donne un rayonnement considérable, national et même international. La maison, les nombreux domestiques, le jeu, la passion de la musique sont autant de moyens de s'afficher. Mais la sensibilité de ce chrétien, la raison de cet homme des Lumières le rendent attentif aux plus pauvres - en particulier à leur éducation - et acteur des institutions charitables. Il prélève sur ses bénéfices la part du pauvre, loge des ouvriers dans l'entreprise. Relevant, malgré l'écart des situations, des similitudes avec l'étaminier Louis Simon, B. Hubert y voit l'influence de l'« esprit d'égalité » (p. 204) façonné par la coutume du Maine.

6 Le titre choisi par Laure Pineau-Defois, « Les plus grands négociants nantais du second xviii siècle dans le cadre de leurs pratiques commerciales : processus d'accumulation du capital », en définit la perspective. L'auteure analyse les différentes formes des entreprises, sociétés individuelles ou familiales, ou véritables sociétés de commerce, mal connues, et mal définies à l'époque. Elle en marque, en les illustrant d'exemples nantais, les modalités juridiques et financières, éclairant ainsi les stratégies diverses des individus et des familles de négociants, dont les facultés d'adaptation remettent en cause "l'idée de l'archaïsme des maisons familiales nantaises » (p. 184). Ces études de cas illustrent au total une diversité d'approches et de problématiques où confluent l'économique, le social, le religieux, le culturel et le politique..., c'est en dire toute la « richesse »! 